\title{
XXXI. Description of a burning mirror, by means of which we may reflect and fix on any object, whether at rest or in motion, the solar rays in as great a quantity as we please. Translated from the French
}

\section{F. Peyrard}

To cite this article: F. Peyrard (1811) XXXI. Description of a burning mirror, by means of which we may reflect and fix on any object, whether at rest or in motion, the solar rays in as great a quantity as we please. Translated from the French , Philosophical Magazine Series 1, 37:155, 176-185, DOI: $10.1080 / 14786441108563263$

To link to this article: http://dx.doi.org/10.1080/14786441108563263

曲 Published online: 18 May 2009.

Submit your article to this journal ๔

Џ Article views: 2

Q

View related articles \lceil 
XXXI. Description of a Burning Mirror, by means of which we may reflect and $f x$ on any Olject, whether at Rest or in Motion, the solar Rays in as great a Quantily as ue please. By F. PEYRARD, Professor of Mathematics in the Bonaparte Lyceum. Translated from the French.

\section{[Concluded from p. 146.]}

My mirror is exempt from all these defects ; for, in proportion as the sun advances, the glasses do not cease to form a parabolic mirror, the axis of which is constantly directed to the sun's centre, passing by the object which we wish to inflame: $i . e$. at each instant my mirror changes its form in order to produce its effect.

Before Buffon, Athanasius Kircher contrived a mirror for burning at 100 fect and upwards. His mirror was a colJection of plain and circular glasses; he placed them on a wall, giving them a proper inclination, in order that the images of the sun might be reflected on the same object.

Aihanasius Kircher made his experiments with five glasses only: he informs us that the heat produced with four glasses was still supportable, and that the heat produced with five was almost insupportable. "I am of opinion," he adds, " that it was with plain mirrors thus arranged that Proclus burned the ships of Vitalian."

Kircher did not push his experiments further, and contented himself with inviting the learned to repeat them with a greater number of glasses*.

It is almost unnecessary to observe that the above has all the defects of Buffon's mirror.

Anthemius of Tralles, who flourished about the end of the fifth century, and was intrusted by Justinian the First, with the building of the temple of St. Sophia at Constantinople, also contrived a burning mirror. A fragment of his,

position, of the earth into like strata or layers of matter, commonly through vast tracts." - Phil. Trans. No. 379, or Reid and Gray's Abridgement, vol. vi. p. 133.

In consequence also of my inquiries, by the same channel, after the papers and maps of the late $\mathrm{Mr}$. Tofield, relating to the British strata, William Smithson, Esq. of Heath near Wakefield, procured a letter to be written to Mr: Willian Tofield of Wath-upon-lerne, a younger son of $\mathrm{Mr}$. $\mathrm{T}$. and has transmitted me his answer, which unfortunately states, that all his father's manuscripts were by his elder brother taken with him into Holland, where he has resided for is years past, and the state of the war has, for one years, prevented any communication with him.-J. F.

* Kircher De arte magna lucis et umilre, lib. x. par. 11. probl. 4. 
in which he gives a description of it, was translated by M. Dupuy, and is to be found in the Memoirs of the Academy of Inscriptions and Belles-Lettres for 1777 . The following are his own words :

\section{"Construct a Machine capable of Uurning at a given Distance by means of Solar Rays.}

"This problem appears impossible, if we adhere to the idea of those who bave explained the method of constructing what are called burning mirrors: for we always find that these mirrors look towards the sun when inflammation is produced; so that if the given spot be not on the same line with the solar rays, if it incline one way or the other, or if it be in an opposite direction, it is impossible to execute what we propose by means of burning mirrors. Besides, the size of the mirror, which ought to be proportioned to the distance to which it is required to send the fire, forces us to acknowledge that the construction, as explained by the ancients, is almost impracticable. Nevertheless, as we cannot take away from Archimedes the glory which is due to him, since it is unanimously allowed that he burnt the enemy's ships by means of the solar rays, reason compels us to admit that the problem is possible. For my part, after having examined the subject, after having considered it with all the attention of which I am capable, I shall explain the method which theory has suggested, after offering a few preliminaries.

"At a given point of a plain Mirror, find a position, such as a Solar Ray coming from any inclination whatever strike this point, and let it be reflected at another point which is also given.

"Let A (fig. 5) be the point given, BA the ray given, according to any direction; and let it so happen that the ray $B A$, falling on a plain mirror and attached to the point $A$, is reflected at the point given $\Gamma$.

"Draw from the puint $A$ to the point $\Gamma$ the straight line $A T$ : divide into two equal parts the angle BAT by the straight line $A \Delta$, and conceive the plain mirror EAZ in a situation perpendicular to the line $A \Delta$, it is evident, from what has been demonstrated, that the ray BA falling on the mirror EAZ will be reflected at the point $\Gamma$; all which must be executed ........

"Consequently all the solar rays equally inclined, and falling parallel to $A B$ on the mirror, will be reflected by parallel lines at Ar. It is therefore demonstrated that, on Vol. 37. No. 155. March 1811., M what. 
whatever side the point $\Gamma$ is, in whatever position it is with respect to the solar ray, this ray will be reflected on the same side by the plain mirror." But inflammation does not take place by means of burning mirrors, unless when several rays are collected in one and the same place, and when the heat is condensed to the burning point. It is thus that, when a fire is kinelled in any place, the parts adjacent and the circumambient air receive a proportionate degree of heat. If, therefore, we conceive that on the contrary all these degrees of heat are collected and concentrated at this place, they will there exert the force of the fire just mentioned. Let us, therefore, bring and collect at the point $\Gamma$ removed from the point $A$ the distance which we have assigned to it, other different rays, by means of plain and similar mirrors, in such a manner that all these ravs, united after reflection, may produce inflammation : this may be effected by means of several persons holding mirrors, which, according to the position indicated, send the rays to the point $\Gamma \ldots \ldots$.

" But in order to avoid the embarrassment resulting from intrusting this operation to several persons, for we shall find that the matter intended to beburnt does not require less than 24 reflections, the following construction must be followed:

"Let $\mathrm{AB} \Gamma \triangle \mathrm{E} Z$ be the hexagonal plain mirror, and other adjoining similar mirrors, and attached to the first accord. ing to the straight lines $\mathrm{AB}, \mathrm{B} \Gamma, \mathrm{\Gamma} \Delta, \triangle \mathrm{E}, \mathrm{EZ}$, \&c. (fig. 6), by the smallest diameter, so that they may be moved on these lines, by means of plates or bands applied, which unite them to each other, or by means of what are called hinges. If, therefore, we bring the surrounding mirrors into the same plane with the mirror in the centre, it is clear that all the rays will undergo a reflection similar and conform to the common position of all the parts of the instrument. But if, the centre mirror remaining as it were immoveable, we dexterously incline upon it all the other mirrors which surround it, it is evident that the rays reflected by them will tend towards the middle of the place where the first mirror is directed. Repeat the same operation, and around the mirrors already described, placing other similar mirrors, all of which may be inclined towards the central mirror, collect towards the same point the rays which they send, so that all these united rays may excite inflammation in the given spot.

"But this inflammation will take place better if you can employ for this purpose four or five of these burning mir- 
rors, and even seven, and if they are all at the same distance from the substance to be burnt, so as that the rays which issue from them, mutually intersecting, may render the inflammation more considerable. For if the mirrors are all in one place, the rays reflected will intersect at very acute angles; so that all the place around the axis being heated, the inflammation will not take place at the single point given. We may also, by means of the construction of these same plain mirrors, dazzle the eyes of the enemy's forces, who, not perceiving those who carry them on their shields, or above their heads, will fall into confusion.

"It is therefore possible, by means of the burning mirrors just mentioned, to carry inflammation to a given distance. Those who have made mention of the mirrors constructed by the divine Archimedes have not said that he made use of a single burning mirror, but of several; and $I$ am of opinion that there is no other way of carrying inflammation to any distance.

"But as the ancients, in treating of common burning mirrors, have not explained in what manner the embola must be traced except by an organic process, without presenting on this head any geometrical demonstration, without even saying that they were conic sections, nor of what kind, nor how they were formed, we shall attempt to give some descriptions of similar embola, not without demonstration, but by geometrical processes.

"Let $\mathrm{AB}$ therefore (fig. 7 ) be the diameter of the burning mirror which we wish to construct, or upon which we wish to operate, and upon the line $\Gamma E \Delta$, which cuts perpendicularly the line $A B$ into two equal parts, let $\Delta$ be the point where we wish the reflection to be made; the point $\mathrm{E}$ being the middle of the line $A B$. Join $B, \Delta$, and by $B$ let there be drawn to $\triangle E \Gamma$ the parallel $B Z$ equal to $B \Delta$; by the point $Z$, the line $Z \Gamma$ parallel to $B A$, cutting at the point $\Gamma$ the line $\Delta E \Gamma$. Cut by the middle $\Gamma \Delta$ to the point $\Theta$, and $\Theta E$ will be the height of the embola relative to the diameter $A B$, as we shall presently see. Divide into as many equal parts as you please the straight line $\mathrm{BE}$; into three, for instance, as in the figure subjoined : viz. $E K, K \Lambda$, and $\Lambda B$, and by the points $K, \Lambda$, draw at $B Z, E \Gamma$, the parallels $\Lambda M, K N$. Afterwards divide in to two equal parts the angle $Z B \Delta$, by the straight line $B \Xi$, the point $\Xi$. being considered as in the middle between the parallels $\mathrm{B} Z, \Lambda \mathrm{M}$. Prolong all these parallels from the side of $\Delta$ towards the points $\Pi, \mathrm{P} ; \Sigma, I$ say that the ray parallel to the axis, $i . e$. to $E \Delta$, and falling by $\Sigma B$ on the mirror at the point $B$, will M 2 
be reflected at the point $\Delta$, nn account of the angle $Z B \Delta$ being divided into two equal parts, and the reflection being made at equal angles, as we have already shown.

"We shall reflect in a similar manner in $\Delta$ the ray $P \Lambda$ in this manner: Draw the straight lines $\Xi \Delta$, $\Xi M$, $\Xi Z$. It is evident that $\Xi \Delta$ is equal to $\Xi Z$, on account of the angle at $B$ being divided equally into two parts. But $\Xi Z$ is equal to $\Xi M$, because from the middle point $\Xi$ they are directed towards the points $Z, M$. Thus $M Z$ is equal to $\Xi \Delta$. Cut, therefore, into two equal parts the angle $M \Xi \Delta$ by the line $\Xi T O$, the point $\mathrm{O}$ being considered in the middle between the parallels $\mathrm{M} \Lambda, \mathrm{NK}$; and this line secting the parallel $M \Lambda$ at the point $T$; we shall demonstrate by the same reasons that $\mathrm{MT}$ is equal to $\mathrm{T} \Delta$, and that $\mathrm{T} \Delta \ldots$. Catera desunt."

The mirror of Anthemius, like that of Buffon, has all the properties, and nothing but the properties; of a parabolic mirror composed of plain glasses. Both these mirrors may set fire to an object, whatever its position may be. The mirror of Anthemius, which is geometrically constructed, is a true parabolic mirror; whereas the mirror of Buffon, when it is adjusted, is a very imperfect parabolic mirror. The focus of the parabolic mirror of Anthemius is invariable; whereas the focus of Buffon's mirror is variable at pleasure. But we should be strangely deceived if we thought that, the position of the object being given and the position of the mirror being also given, we could set fire to an object at any hour of the day or any day of the year. These two mirrors cannot produce all their effects, except at the very moment when the sun is at the same point in the heavens at which it was when the mirror of Anthemius was constructed, and when that of Buffon was adjusted.

It now remains to speak of the burning mirror of Archimedes, with which he is said to have burned the fleet of Marcellus before the nalls of Syracuse.

The ancient authors who speak of this mirror are Lucian, Galienus, Authemius of Tralles, Eustathius, Tzetzes and Zonaras.

Lucian says, in his Hippias, that Archimedes, by a singular artifice, reduced the ships of the Romars to ashes.

Galienus expresses himself in the following manner: "It is in this way, at least I think so, that Archimedes burnt the enemy's vessels. For, by the belp of a burning mirror, we may easily set fire to wool, hemp, wood, \&zc. and, in short, to any thing dry and light *."

* De Temperamentis, lib. iii. cap. 2.

Anthemius, 
Anthemius, who flourished at the commencement of the sixth century, informs us that it was unanimously allowed that Archimedes burned the encmy's vessels by means of the solar rays.

Eustathius, in his commentary on the Miad, says that Archimedes, by an invention in catoptrics, burned the fleet of the Romans at a distance equal to the shot of an arrow from a bow.

"Archimedes," says Zonaras (Annal. lib. ix.) "burnt the fleet of the Romans in an admirable manner; for he turned a certain mirror towards the sun, and which received its ravs. The air having been heated on account of the density and smoothness of this mirror, he kindled an immense flame, which he precipitated on the vessels which were in the harbour and reduced them to ashes."

"When the fleet of Marcellus was within bow-shct," says Tzetzes, "the old man (Archimedes) brought out a hexagonal mirror which he had made. He placed at proper distances from this mirror other smaller mirrors which were of the same kind, and which were moved by means of their hinges and certain square plates of metal. He afterwards placed his mirror in the midst of the solar rays, precisely at noon day. The rays of the sun being reflected by this mirror, he kindled a dreadful fire in the ships, which were reduced to ashes at a distance equal to that of a bow shot..... Dion and Diodorus, who wrote the life of Archimedes, and several other authors, speak of this fact; but chiefly Anthemins, who wrote on the prodigies of mechanics; Hero, Philo, Pappus, and in short all who have written on ancient mechanics: it is in these works that we read the history of the conflagration occasioned by the mirror of Archimedes."

Such are the authorities on which the history of the burning mirrors of Archimedes is founded, and these authorities are in my opinion of great weight. The silence of Polybius, of Livy, and of Plutarch, however, who relate at great length. what Archimedes did for the defence of Syracuse, seems to warrant a doubt as to the fact of the burning the fleet of Marcellus. But whether Archimedes. did or did not burn the fleet of Marcellus, it is certain that be contrived a burning mirror, and that this mirror was an assemblage of plain mirrors.

But what was the burning mirror of Archimedes? I shall endeavour to answer this question, after I shall have made some observations on the different kinds of parabolio mirrors composed of plain glasses. 
Take a parabolic conoid, the axis of which is constantly directed to the centre of the sun : let us suppose that some plain glasses are tangent to this conoid, and suppose that this conoid is cut by a vertical plane which passes by its axis. If we cut this conoid by a plane perpendicular on the axis, we shall have, on the side of the summit, a burning mirror composed of plain glasses which will not inflame an object, except in so far as it is placed directly between the mirror and the sun. If we cut the conoid by a plane which is perpendicular on the vertical plane, and which passes between the sun and the zenith, the upper segment will give a burning mirror which will set fire to an object from top to bottom; and the other segment will give a mirror which will set fire to it from bottom to top, provided this object is in the vertical plane of which we have been speaking. Lastly, let us suppose that the secting plane is not perpendicular on the axis, and that it forms with the horizon an acute angle, whether the secting plane passes by the axis, or whether it cuts or does not cut the axis, one of the burning mirrors which will result from this section will inflame from top to bottom, the other from bottom to top, any object which is placed to the right or left of the sun, and this is the case with the mirror of Anthemius as well as with that of Buffon.

This being granted, let us return to the burning mirror of Archimedes. Anthemius relates that in the descriptions which the ancient authors gave of burning mirrors, we always find that these mirrors faced the sun, when the inflammation was produced, and that the object set fire to was neither to the right nor to the left. Hence I conclude, that the mirror of Archimedes was one of the segments of the parabolic conoid just mentioned, when the secting plane is perpendicular on the vertical plane.

Tzetzes informs us that the mirror of Archimedes was a collection of hexagonal mirrors, which moved by means of their hinges and certain plates of metal, i. e. that the mirrors of Archimedes were arranged in such a way that each could be moved in every direction, as in Buffon's mirror; and so far the mirror of Buffon does not differ from that of Archimedes, except in so far as the mirrors being rectangular in the former and hexagonal in the latter.

Tzetzes adds that Archimedes placed his mirror in the midst of the solar rays at noon day: $i . e$. he placed his mirror perpendicular to the plane of the equator. If the mirror of Archimedes had not been intended to produce inflam- 
inflammation, except at the moment when the sun was in a plane perpendicular upon the plane of the mirror and the plane of the horizon, it is evident that it would have been indifferent whether this mirror was or was not plaeel perpendicularly on the plane of the equator. But wherefore did Archimedes place his mirror perpendicularly on the plane of the equator? It was in order that his mirror might reflect the solar rays on the same object during the whole time that the sun was on the horizon, and I shall show that the mirror thus placed was capable of producing this effect in two different ways.

Let $A B$ (fig. 8) be an iron rod parallel to the axis of the globe. Let $C D$ be an iron rod perpendicular upon $A B$; let $E F$ be the mirror of Archimedes, and let it be placed in such a way that the iron branch $C D$ is perpendicular on its plane when prolonged. It is evident that this mirror, when so placed, will be perpendicular on the plane of the equator. Let us suppose that by means of a screw, as we see in fig. 9, we can move the iron rod $A B$ on itself. This being done, let any person, on turning the screw, be desired to keep the mirror in a position perpendicular on the vertical plane which passes by the axis of the iron rod $A B$ and. $b$ the centre of the sun, and that another person is employed to adjust the mirror in such a way that the images reflected may be carried to a point $D$, taken on the iron rod CD.

If during the whole day we retain by means of the screw the mirror in a position perpendicular on the vertical plane which passes by the axis of the iron rod $A B$ and by the centre of the sun, it is evident that the images refected at the point $D$ will remain there fixed, without vibrating and without displacing the focus : for, if the contrary happened, it would be because in the space of twelve or fifteen hours the sun would approach or remove from the equator in a sensible manner; which is not the case.

In the second place, let there be a piece of iron ACDEB (fig. 9) : let its extrenities $\mathrm{AC}, \mathrm{EB}$, be cylindrical, and let the part CDE be flattened and bent into a semicircle; let the axes of the cylinders $\mathrm{AC}, \mathrm{EB}$, be in the straight line $A B$, and let this straight line be parallel to the axis of the earth; let the piece of iron $A C D E B$ be moveable around the axis $A B$, and let $L I$ be a screw ; let $D K$ be the mirror of Archimedes; let this mirror be placed parallel to $A B$ and perpendicular to the plane which passes by the axis of 
the straight line $A B$ and by the point $D$, the middle of the band CDE. It is evident that the mirror DK will be placed perpendicularly to the plane of the equator.

This being done, let a person by turning the screw KL be instructed to keep the mirror in a position perpendicular on the vertical plane which passes by $A B$, and by the centre of the sun, and let another person adjust the mirror so as that the images reflected may be borne on a point $\mathrm{L}$ of the axis. The mirror being adjusted, it is evident that the images reflected at the point $\mathrm{D}$ will there remain fixed during the whole of the time that the sun is upon the horizon.

By means of a quadrant $\mathrm{GG}$ and a needle fixed with the axis $A B$, it will be easy, the hour of the day being known, to keep the mirror in its proper position.

I have demonstrated that, the burning mirror of Archimedes remaining perpendicular on the piane of the equator, it would be possible to fix on an object the solar images during the whole of the time that the sun was upon the horizon, and I have shown that this might be done in two ways. But it is evident that with the constructions which I have given, the thing is not physically possible, except when the distance between the object to be inflamed and the mirror does not exceed certain limits. It remains to show, that by modifying the second construction we may set fire to an object placed at a great distance.

While the straight line $D K$ turns round the axis $A B$, the perpendicular drawn from the point $K$ on $A B$ engenders a circle parallel to the equator, and the straight line drawn from the point $K$ parallel to $A B$ engenders an ellipsis in the horizontal plane. Hence it follows that if we move the mirror DK in such a manner that this straight line prolonged moves according to the horizontal ellipsis, and that the point $D$ is moved according to the circumference of the circle parallel to the equator, the plane of the mirror remaining always parallel to the axis of the earth and perpendicular upon the vertical plane which passes by the centre of the sun and by the centre of the mirror, it is evident that the images reflected by the mirrors would remain fixed at the point $\mathrm{L}$, as before.

This being done, let us see how we should proceed to burn an object placed at a great distance:

The height of the pole and the distance of the object to be set fire to being known, the ellipsis which it is requisite 
to trace upon the horizontal plane is determined. This ellipsis being traced, we move the mirror in the same way as in fig. 9 , by means of a machine which it would be easy to contrive. Hence I conclude, that by following the same principles as before we may burn an object placed at a great distance. In this manner therefore Archimedes may have burnt the fleet of Marcellus.

It will be easy to perceive that the mirror EF (fig. 8) and DK (fig. 9) might have an oblique position on the plane of the equator, provided in the two cases it was fixed with the straight line $A B$ perpendicular on the plane of the equator.

I shall conclude this essay with two observations. If the mirror DK, instead of having a fixed position, was moveable in the iron band CDE (fig. 9), and if this mirror was adjusted in order to carry the images to $R$ the middle of $\mathrm{CE}$, it is evident that if we made this mirror have its axis $Y Z$ constantly directed to the sun's centre, the focus would remain at the point $R$ during the whole day and every day of the year.

I call the axis of a burning mirror the axis of the conoid, one part of the surface of which forms the burning mirror.

Upon the same principles it would be easy to make a mirror of refraction, so as to keep its focus constantly at the same point.

Let $A B$ (fig. 10) be an iron rod parallel to the axis of the earth; let CDE be an iron band folded into the arc of a circle, having for its centre the point $M$ taken on the axis of the rod $A B$; let $K L$ be a glass moveable round an axis perpendicular on the plane which passes by $A B$ and by the middle of the band CDE. Let us suppose that by means of a screw, we keep, during the whole time that the sun is upon the horizon, the glass parallel to the sun; it is evident that the focus $Q$ will remain fixed at the same point of a hollow RDS placed on the band CDE.

\section{On Tuning Musical Instruments. By a CoR- RESPONDENT.}

To Mr. Tilloch.

SIR, $W_{\text {Ithour entering at all into the disputes about }}$ words, the characters of authors; what silly tuners do, or say; and whether fifths should be this or that way tem- 